\title{
Doppler US and CT Diagnosis of Nutcracker Syndrome
}

\author{
Seung Hyup Kim, MD ${ }^{1,2}$ \\ ${ }^{1}$ Department of Radiology, Seoul National University Hospital, Seoul, Korea; ${ }^{2}$ Kidney Research Institute, Seoul National University College of \\ Medicine, Seoul, Korea
}

Nutcracker syndrome (NCS) is a syndrome caused by compression of the left renal vein (LRV), between the abdominal aorta and the superior mesenteric artery, resulting in hypertension of the LRV and hematuria. Doppler ultrasonography (US) has been commonly used for the diagnosis of NCS. However, several technical issues, such as Doppler angle and sample volume, need to be considered to obtain satisfactory results. In addition, morphologic changes of the LRV and a jetting phenomenon across the aortomesenteric portion of the LRV on contrast-enhanced computed tomography (CECT) are diagnostic clues of NCS. With proper Doppler US and CECT, NCS can be diagnosed noninvasively.

Keywords: Nutcracker syndrome; Left renal vein; Renal vein hypertension; Doppler US; Contrast-enhanced CT

\section{INTRODUCTION}

The first description of left renal vein (LRV) entrapment was published in 1950 (1). After the abdominal aorta and superior mesenteric artery (SMA) were described as two arms of a nutcracker, the condition was named nutcracker syndrome (NCS) by de Schepper in $1972(2,3)$. The mechanism of NCS is similar to duodenal obstruction in SMA syndrome (4).

NCS can be suspected from the clinical history and a urine erythrocyte morphology of predominantly isomorphic erythrocytes. A cystoscopic finding of left-sided hematuria is a supporting evidence for NCS. However, because hematuria is often intermittent, it is sometimes not detected even when cystoscopy is performed.

Various imaging modalities are used for NCS diagnosis, including Doppler ultrasonography (US), contrast-enhanced computed tomography (CECT), and magnetic resonance

Received March 22, 2019; accepted after revision July 17, 2019. Corresponding author: Seung Hyup Kim, MD, Kidney Research Institute, Seoul National University College of Medicine, 101 Daehak-ro, Jongno-gu, Seoul 03080, Korea.

- Tel: (822) 2072-3259 • Fax: (822) 743-6385

- E-mail: kimshrad@snu.ac.kr

This is an Open Access article distributed under the terms of the Creative Commons Attribution Non-Commercial License (https://creativecommons.org/licenses/by-nc/4.0) which permits unrestricted non-commercial use, distribution, and reproduction in any medium, provided the original work is properly cited. imaging (MRI); however, diagnosis of NCS is challenging because the diagnostic algorithm and criteria are not well established (5). Although a pressure gradient of more than $3 \mathrm{~mm} \mathrm{Hg}$ between the LRV and the inferior vena cava (IVC) is regarded as the most definitive diagnostic criterion for NCS, it is not clear whether the invasive procedure needed to measure the pressure gradient is truly required for the diagnosis of NCS $(5,6)$.

In 1996, we reported that Doppler US is useful for making a diagnosis of NCS noninvasively in adults (7), and a similar result was later also reported from our institution for the diagnosis of NCS in children (8). CECT is also commonly used as an imaging study for the evaluation of patients with hematuria of unknown causes. In 2011, we reported that findings of LRV on CECT of the kidney may be useful for diagnosing NCS (9).

The purpose of this article is to review the usefulness of Doppler US, with its technical considerations, and CECT findings of the LRV in patients with NCS.

\section{Nutcracker Syndrome}

NCS refers to a syndrome caused by significant compression of LRV between the abdominal aorta and SMA, resulting in hypertension of the LRV and hematuria due to rupture of the thin-walled veins close to the calyceal fornices $(10,11)$. NCS typically causes intermittent gross hematuria but may be accompanied by microscopic 
hematuria, proteinuria, or left flank pain, without gross hematuria (12-17).

The term "NCS" should not be used interchangeably with the term "nutcracker phenomenon" (NCP), which is simply a phenomenon of aortomesenteric (AM) compression of the LRV $(10,18)$. There have been two reports regarding NCP $(19,20)$, which showed that asymptomatic compression of the AM portion of the LRV is a very common phenomenon. The incidence of the diameter of the LRV lateral to the aorta being more than $50 \%$ greater than that at the AM portion was $72 \%$ in one report (19) and $51.3 \%$ in the other (20). NCS is a term that should be used only when symptoms are present in addition to the NCP $(10,18)$.

The incidence of NCS is unknown. However, considering the high incidence of unexplained hematuria and proteinuria and the high incidence of asymptomatic compression of the AM portion of the LRV, we may assume that NCS may not be a rare entity and the prevalence may be higher than previously thought $(7,19-22)$. NCS typically occurs in young and slender patients because of the scanty amount of intra-abdominal fat and the narrow angle between the aorta and SMA (Fig. 1). However, NCS may also occur in non-slender patients if the LRV is stretched over the aorta (Fig. 2) (23).

Several variations of NCS are associated with anatomic variations of the LRV. Retroaortic LRV, where the retroaortic portion of the circumaortic LRV may be compressed between the aorta and vertebra, can result in posterior NCS (Fig. 3) (24-28). NCS may also occur in patients with a leftsided IVC or double IVC, where the LRV is not compressed anatomically, but the prominent flow from the lower
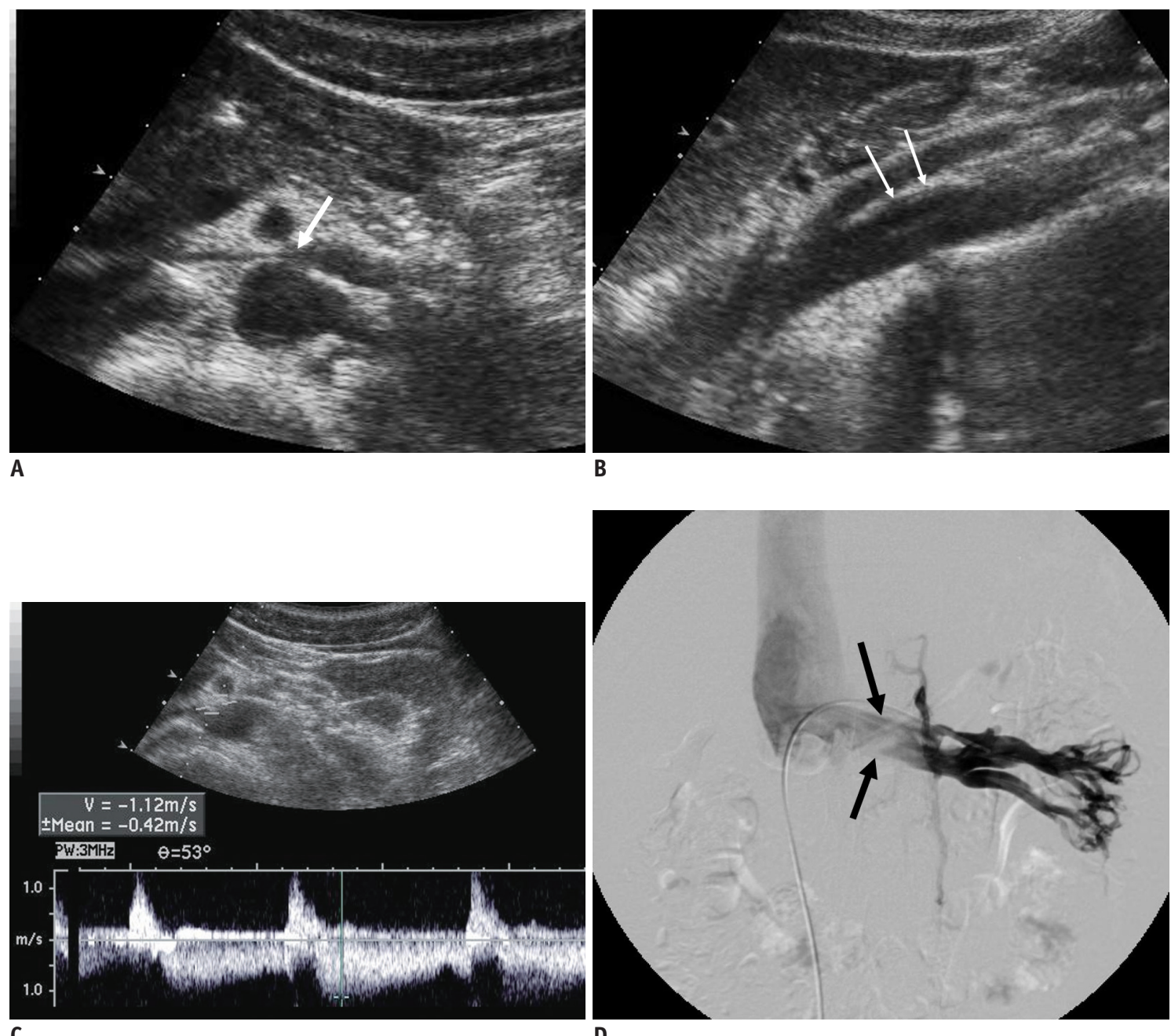

Fig. 1. 18-year-old male patient with NCS.

A. Transverse US of LRV shows compression of LRV at AM portion (arrow). B. Sagittal US of aorta and SMA shows slit-like LRV (arrows), compressed between two vessels. C. Spectral Doppler US of LRV at AM portion shows clear venous flow spectrum, with PV of $112 \mathrm{~cm} / \mathrm{s}$. D. Left renal venogram shows compression of LRV at AM portion (arrows). Pressure gradient measured across AM portion of LRV was $4 \mathrm{~mm} \mathrm{Hg}$. AM = aortomesenteric, $\mathrm{LRV}=$ left renal vein, $\mathrm{NCS}=$ nutcracker syndrome, $\mathrm{PV}=$ peak velocity, SMA = superior mesenteric artery, US = ultrasonography 


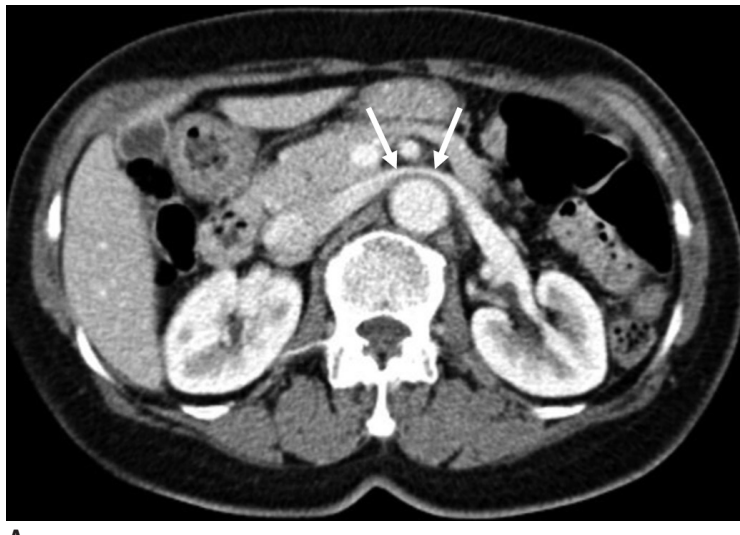

A

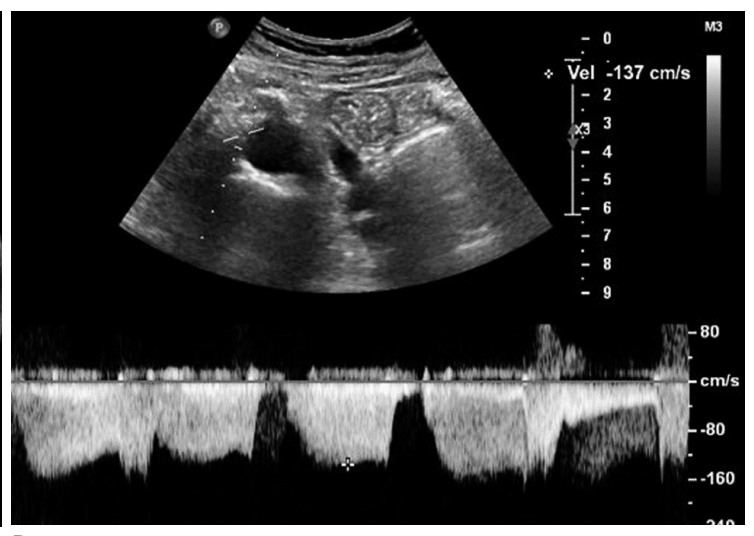

B

Fig. 2. 72-year-old female patient with NCS.

A. CECT scan shows LRV (arrows) stretched over aorta, without any compression between aorta and SMA. B. Spectral Doppler US of LRV measured at $\mathrm{AM}$ portion shows $\mathrm{PV}$ of $137 \mathrm{~cm} / \mathrm{s}$. CECT = contrast-enhanced $\mathrm{CT}$

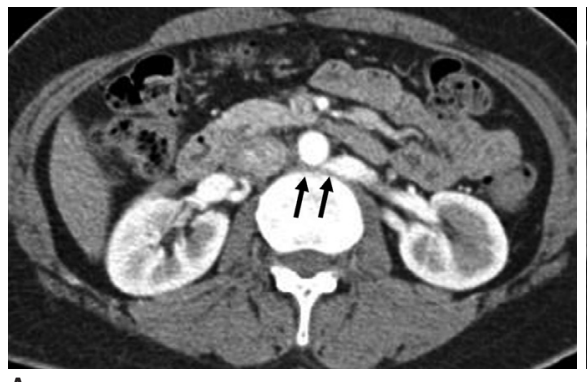

$\bar{A}$

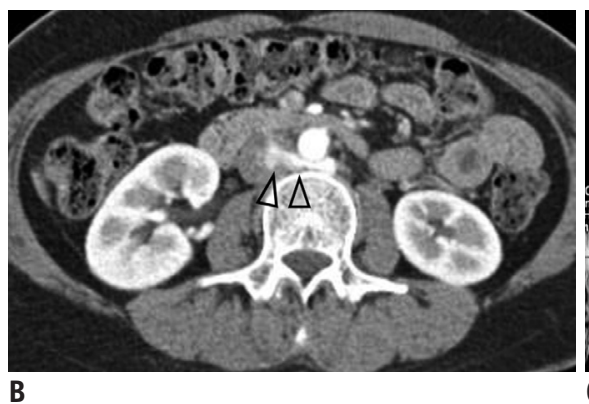

B

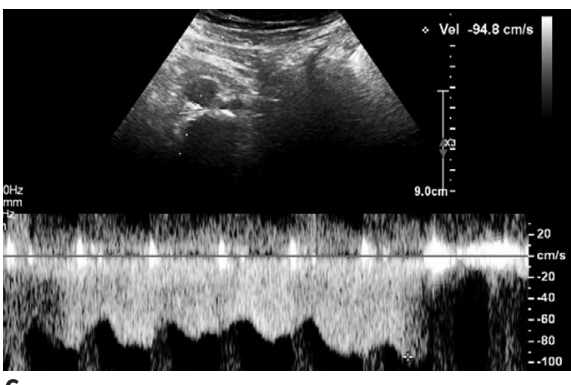

C

Fig. 3. 49-year-old female patient with posterior NCS.

CECT images in early cortical phase show retroarotic LRV (arrows) (A) compression between abdominal aorta and vertebra. Jetting phenomenon of contrast-opacified venous flow (arrowheads) (B) into IVC can be seen. C. Spectral Doppler US of retroaortic LRV shows high PV of $94.8 \mathrm{~cm} / \mathrm{s}$. IVC $=$ inferior vena cava

extremity may cause functional obstruction of venous flow from the left kidney (Fig. 4). Rare variations of NCS also include NCS caused by the left testicular artery arching over the LRV (29) and right-sided NCS due to compression of the right renal vein in pregnant women (30).

\section{Diagnosis of Nutcracker Syndrome}

Repeated hematuria, either gross or microscopic, in an otherwise healthy patient is a disturbing and perplexing problem, both to the patients and the physicians, because extensive diagnostic procedures are necessary to establish a confirmative diagnosis (7). In this context, suggesting NCS as a likely cause of unexplained hematuria is important in the management of such patients, because it allows a more relaxed work-up of hematuria.

The pressure gradient between the LRV and IVC can be measured directly through invasive catheterization. In the normal population, the pressure gradient between the LRV and IVC is less than $1 \mathrm{~mm} \mathrm{Hg}$. If this pressure gradient exceeds $3 \mathrm{~mm} \mathrm{Hg}$, a definitive diagnosis of NCS can be made $(6,31)$.

NCS may be suspected noninvasively on the basis of a causative anatomical change, i.e., compression of the LRV between the aorta and SMA. Such anatomical changes can be seen using any three-dimensional imaging technique, such as US, CT, or MRI (7-9). Previous studies using US have compared the diameters of the LRV at the renal hilar and AM portions $(7,8)$. In our early report using US $(7)$, the mean ratio of the diameter differed significantly between NCS and normal groups: $5.0 \pm 2.3$ in the NCS group (range, 2.6-11.0) and $3.3 \pm 1.1$ in the normal group (range, 2.0-6.0). In two CT studies, the mean ratio was also significantly different between the NCS group and control group $(11,32)$. However, in a later study that recruiting pediatric subjects, the mean ratio was not significantly different between the two groups: $5.3 \pm 1.4$ in the NCS group and $4.7 \pm 1.9$ in the control group (8). Although the diameter ratio was significantly different in three of the four aforementioned studies $(7,8,11,32)$, we should keep in mind that there 

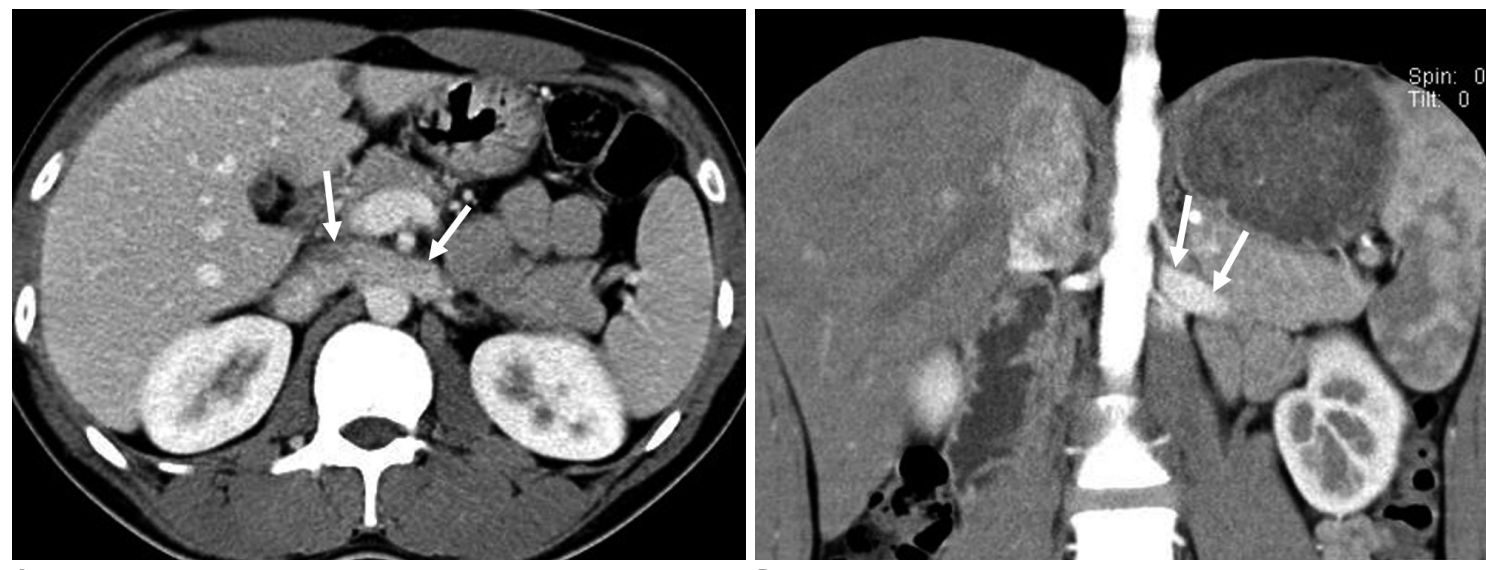

A

B
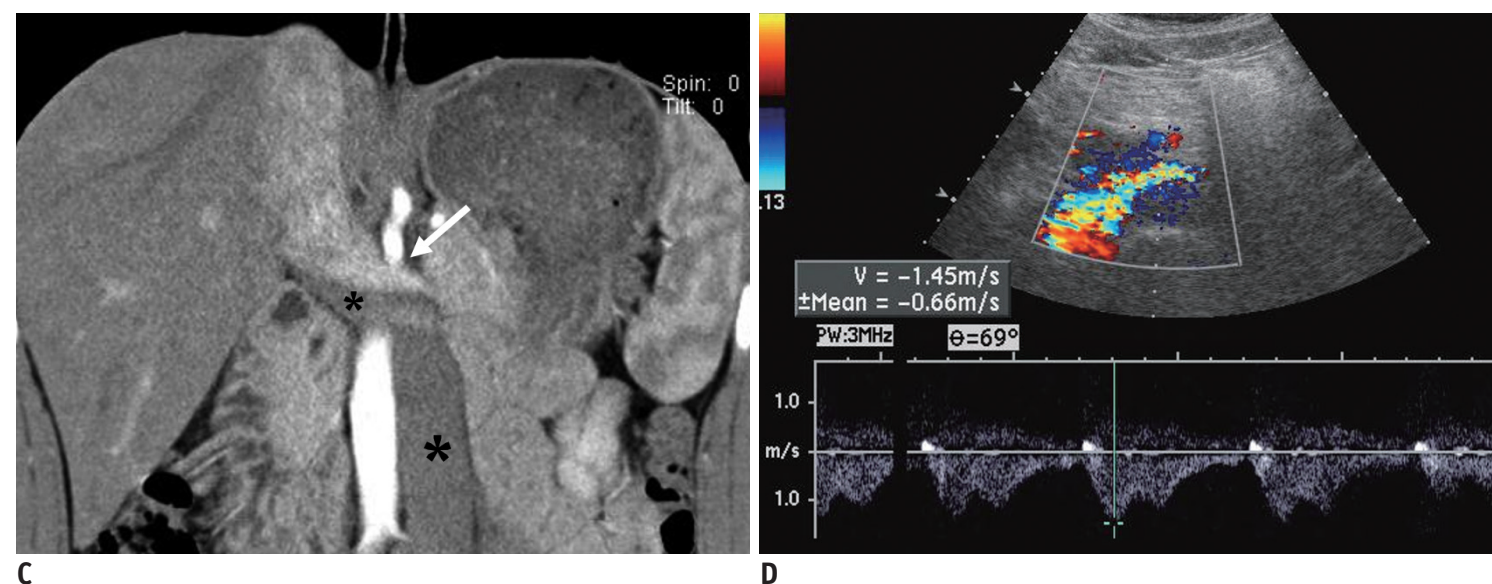

D

Fig. 4. NCS in 20-year-old male patient with left-sided IVC.

A. CECT image shows well-preserved lumen in LRV (arrows), without any compression between aorta and SMA. B, C. Coronal CECT images show left-sided IVC crossing midline and continuous with right-sided suprarenal IVC. Note contrast-opacified venous flow from LRV (arrows), which is compressed by non-opacified venous flow from lower part of body thought left-sided IVC (asterisks). D. Spectral Doppler US performed at midline-crossing of vessel reveals high PV of $145 \mathrm{~cm} / \mathrm{s}$. In this patient, LRV is not compressed anatomically, but venous flow from left kidney is hemodynamically impeded by dominant venous flow from lower extremity through left-sided IVC.

are situations in which applying a diameter ratio criterion in clinical practice is difficult, especially when diameters are measured using US. This is because compression by the US transducer, to demonstrate the LRV better, may cause additional compression of the LRV.

Another anatomic parameter that can be used for the diagnosis of NCS is the angle between the abdominal aorta and the SMA, i.e., the AM angle that can be measured in the sagittal imaging plane. A normal AM angle is reported to have a wide range, between $45^{\circ}$ and $90^{\circ}(22,33-35)$. In NCS patients, the AM angle is significantly narrower than that in the normal population. However, because there is also a significant overlap between NCS and normal groups, it is difficult to use this angle in practice (36). In addition, an AM angle may differ significantly according to the position of the patient, i.e., supine or upright (37).

\section{Doppler Ultrasonography}

Because Doppler US may be the easiest way to measure blood flow velocity in the body, it can be used for the diagnosis of NCS. In our previous studies $(7,8)$, the mean peak velocity (PV) of the LRV was $14.2 \pm 2.5 \mathrm{~cm} / \mathrm{s}$ at the renal hilar portion and $110.7 \pm 35.8 \mathrm{~cm} / \mathrm{s}$ at the AM portion in NCS adults (7), and $21.5 \pm 5.0 \mathrm{~cm} / \mathrm{s}$ at the renal hilar portion and $139.6 \pm 31.0 \mathrm{~cm} / \mathrm{s}$ at the AM portion in NCS children (8). In the normal control group, however, it was $18.6 \pm 3.7 \mathrm{~cm} / \mathrm{s}$ at the renal hilar portion and $50.9 \pm 27.9 \mathrm{~cm} / \mathrm{s}$ at the $A M$ portion in adults (7), and $21.2 \pm 5.2 \mathrm{~cm} / \mathrm{s}$ at the renal hilar portion and $72.4 \pm 24.4 \mathrm{~cm} / \mathrm{s}$ at the AM portion in children (8). In those two studies, we suggested that the best PV ratio cutoff values for the differentiation of the NCS from the normal group was 5.0 in adults, with a sensitivity of $80 \%$ and a 
specificity of $94 \%$ (7), while it was 4.7 in children, with a sensitivity of $100 \%$ and a specificity of $90 \%$ (8). Therefore, if the PV of the LRV at the AM portion is approximately 5 times higher than that at the hilar portion in both adults and children, we may suspect NCS.

\section{Estimation of Pressure Gradient from Doppler Ultrasonography}

In a healthy population, there is no remarkable pressure gradient (it is usually less than $1 \mathrm{~mm} \mathrm{Hg}$ ) between the LRV and the IVC $(25,38)$. Therefore, if the pressure gradient between the LRV and IVC is more than $3 \mathrm{~mm} \mathrm{Hg}$, a diagnosis of NCS can be made. Even though the pressure gradient between the two vessels needs to be determined by invasive catheterization, we may estimate the pressure gradient theoretically from the flow velocity obtained through Doppler US. For Doppler US, Bernoulli's principle of continuity for ideal and incompressible liquid may be applicable. The relevant equation is $\left(\mathrm{P} 1+1 / 2\left[\rho \mathrm{v} 1^{2}\right]+\right.$ $\left.\rho g h 1=P 2+1 / 2\left[\rho v 2^{2}\right]+\rho g h 2\right)$ where $P$ is pressure, $v$ is velocity, $\mathrm{h}$ is elevation, $\rho$ is density, and $\mathrm{g}$ is acceleration due to gravity. For blood in the human body, because $h$ is negligible, we may simplify the equation to ( $P 1+1 / 2$ $\left.\left[\rho \vee 1^{2}\right]=\mathrm{P} 2+1 / 2\left[\rho \vee 2^{2}\right]\right)$. Consequently, this equation may be changed to $\left(\mathrm{P} 1-\mathrm{P} 2=1 / 2 \rho\left[\mathrm{v} 1^{2}-\mathrm{v}^{2}\right]\right)$ where P1 - P2 is the pressure gradient between the two points. Because $1 \mathrm{~mm} \mathrm{Hg}$ is $1333 \mathrm{~g} / \mathrm{cm} / \mathrm{s}^{2}$ and the density of blood $(\rho)$ is approximately $1.06 \mathrm{~g} / \mathrm{cm}^{3}$, we may calculate a theoretical pressure gradient in $\mathrm{mm} \mathrm{Hg}$ unit using two PV values at the hilar and AM portions of the LRV. However, we should be aware that, in NCS patients, there may be some differences between a theoretically estimated pressure gradient and the true measured gradient, because of collateral venous pathways.

\section{Practical Tips for Doppler Ultrasonography}

An accurate measurement of the PV of the LRV at the hilar and AM portion is an integral part of Doppler US-based

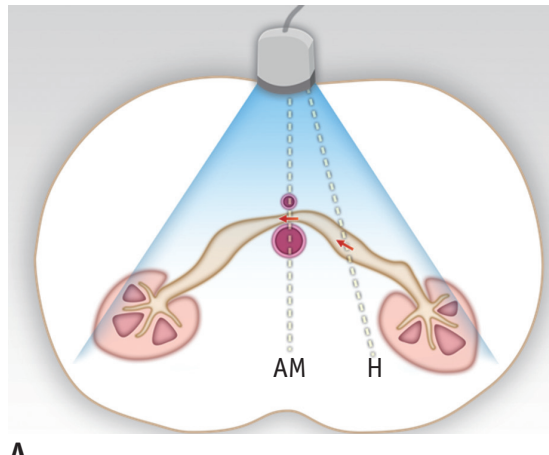

A

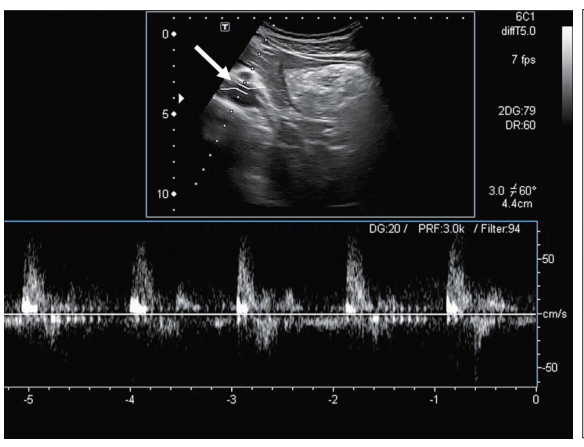

D
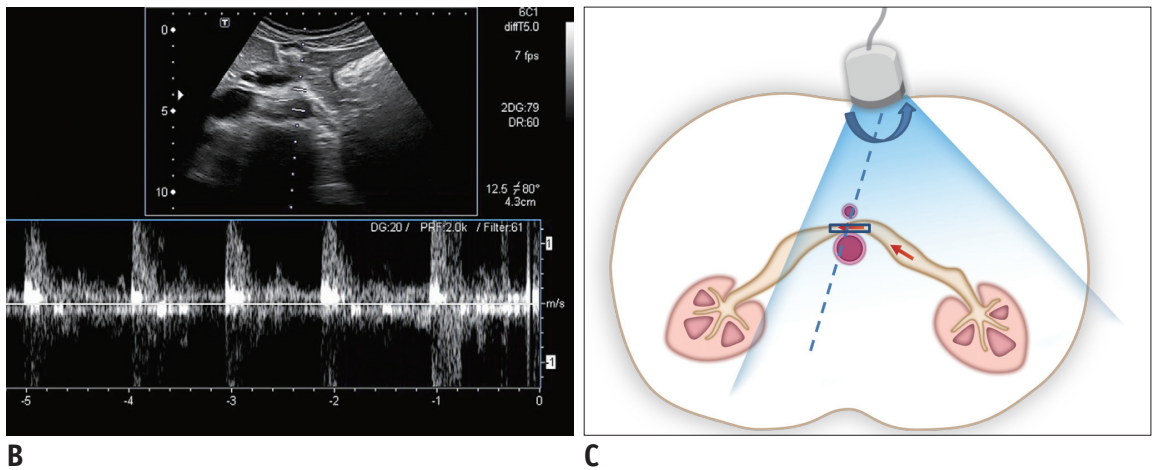

Fig. 5. Schematic drawing of Doppler US of LRV and spectral Doppler US images of LRV.

A. With usual position of US transducer in transverse plane, Doppler angle is optimal to obtain clear spectrum for hilar portion of LRV (H), while angle for AM portion of LRV is around $90^{\circ}$. Arrows indicate direction of blood flow and dotted lines indicate direction of ultrasound beam. B. Spectral Doppler US image of LRV obtained at AM portion shows noisy spectrum from aorta. Therefore, it is almost impossible to measure flow velocity in LRV. C. With slight shift of transducer to left and subtle counterclockwise rotation (curved arrow) until AM portion of LRV is located in left corner of US image, Doppler angle for AM portion of LRV can be adjusted. Arrows indicate direction of blood flow and dotted line indicates direction of ultrasound beam. D. Even with adjustment of Doppler angle, Doppler spectrum from LRV is still not clear, because LRV is not properly located due to small sample volume (arrow). E. In addition to adjustment of Doppler angle, increasing sample volume may help LRV be continuously included within sample volume between pulsating aorta and SMA. Arrows indicate direction of blood flow and dotted line indicates direction of ultrasound beam. F. Doppler spectrum from LRV now becomes optimal, with PV of approximately $150 \mathrm{~cm} / \mathrm{s}$. 
diagnosis of NCS, but several technical issues need to be considered to obtain satisfactory results. The first tip for proper Doppler US scanning is optimization of the Doppler angle. It is easy to obtain a satisfactory Doppler spectrum at the hilar portion of the LRV, because the Doppler angle is usually within an optimal range between $30^{\circ}$ and $60^{\circ}$ (Fig. $5 A, B)$. However, obtaining an optimal Doppler spectrum at the AM portion of the LRV is sometimes difficult. If the operator holds the US transducer in the usual transverse direction, the angle between the US beam and the AM portion of the LRV is approximately $90^{\circ}$ (Fig. 5A). With this Doppler angle (i.e., $90^{\circ}$ ), it is almost impossible to obtain a clear Doppler spectrum and measurement errors become significant, even if a spectrum can be obtained. To

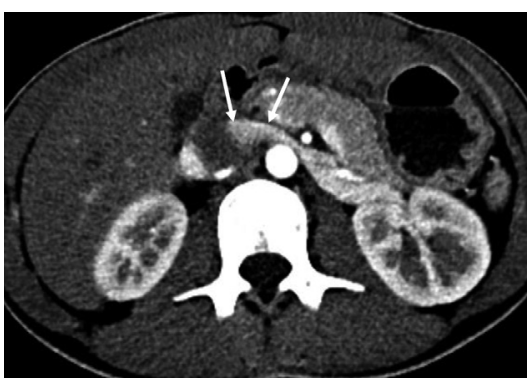

A

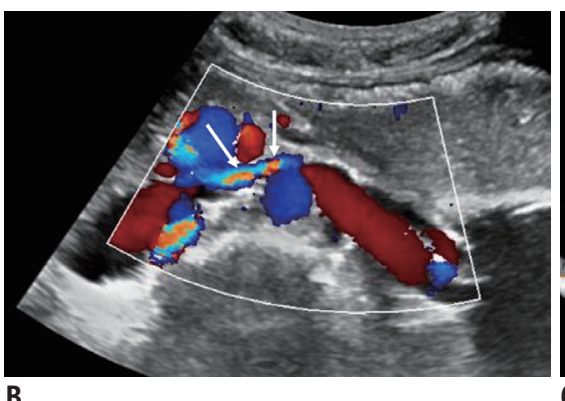

B

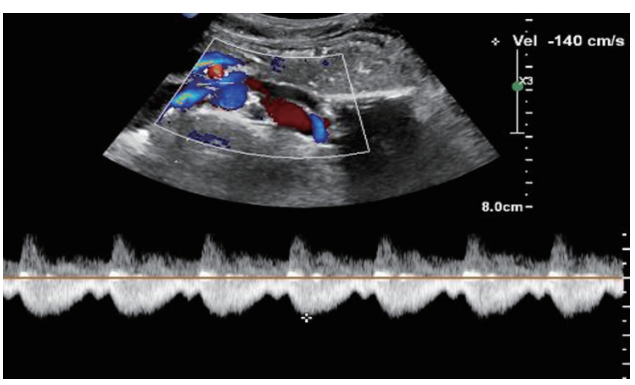

Fig. 6. 17-year-old woman with NCS.

A. CECT scan shows compression of LRV between aorta and SMA. Note contrast-opacified venous flow along anterior non-dependent portion of IVC (arrows). B. Color Doppler US of LRV shows bright color flow signal (arrows) at AM portion of LRV due to aliasing artifacts caused by high flow velocity. C. Spectral Doppler US at AM portion of LRV shows PV of $140 \mathrm{~cm} / \mathrm{s}$.

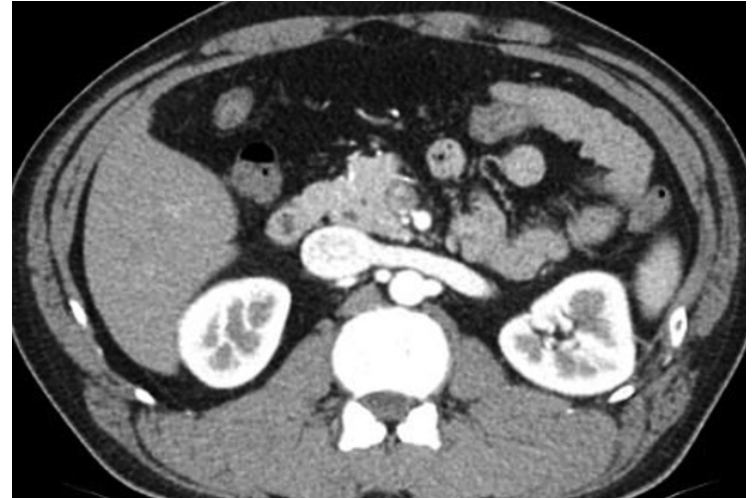

A

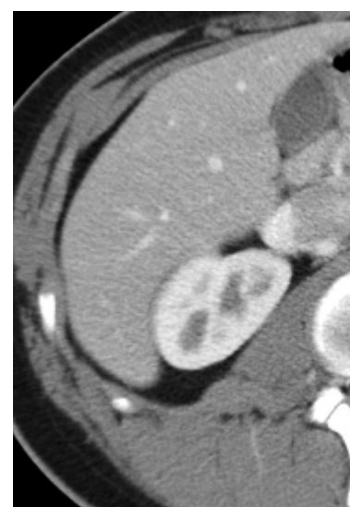

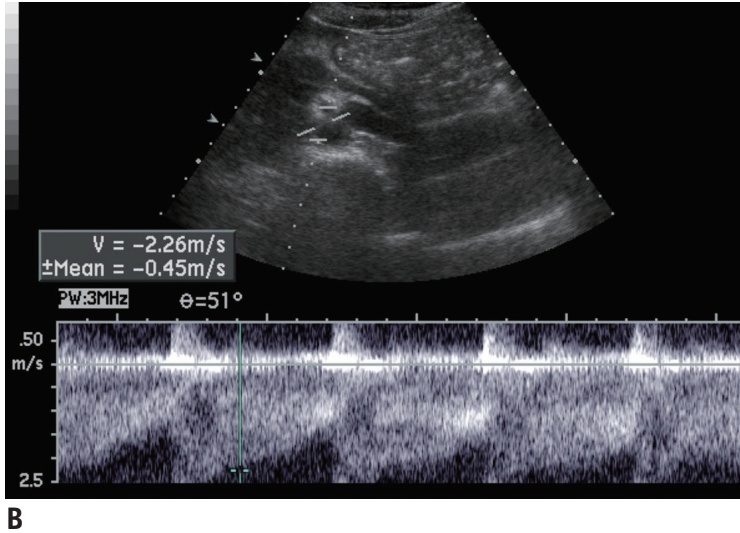

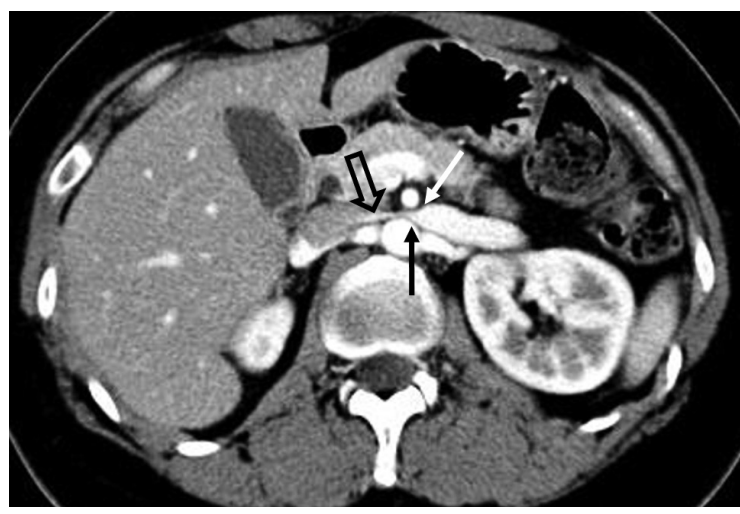

D

Fig. 7. CECT of kidney in early cortical phase.

A. 45-year-old male without hematuria. CECT shows normal LRV without compression at AM portion and homogeneously opacified LRV and IVC. B, C. 17-year-old male with NCS. B. Doppler US of LRV at AM portion shows high PV $(226 \mathrm{~cm} / \mathrm{s})$ of LRV. C. CECT in early cortical phase shows jetting of contrast-opacified venous flow (arrow) into IVC across AM portion of LRV. D. 28-year-old female with NCS. CECT shows severely compressed LRV at AM portion, with beak sign (arrows). Note jetting (open arrow) of contrast-opacified venous flow into IVC across AM portion of LRV. 
obtain an optimal Doppler angle at the AM portion of the LRV, we should adjust the position and the direction of the transducer by slightly moving it to the left and rotating it counterclockwise, until the AM portion of the LRV is located in the left corner of the US image (Fig. 5C, D).

The second tip is the optimal adjustment of the sample volume during Doppler US. Even though a proper Doppler angle is achieved by rotating the transducer, we may not obtain a satisfactory spectrum if a small sample volume is used. With a small sample volume, the target vessel (i.e., the AM portion of the LRV) may not be included within the sample volume due to pulsation of the aorta and SMA (Fig. 4B). Therefore, the sample volume should be wide enough to include the AM portion of the LRV between the pulsating aorta and SMA, throughout the entire cardiac cycle (Fig. 5E, F). Color Doppler US (CDUS) can sometimes be useful for the diagnosis of NCS, by showing bright colors of high velocity due to aliasing artifacts from the jetting flow immediately distal to the AM portion of the LRV (Fig. 6). The observation of a jetting flow on CDUS may also be helpful in determining the appropriate sample volume during spectral Doppler US.

\section{Contrast-Enhanced CT}

CECT is commonly used to evaluate patients with hematuria of unknown causes. Although NCS is one of the important causes of hematuria, the CT findings that may suggest NCS are not yet well established. In our previous report (9), various CT parameters, such as a beak sign, beak angle, LRV diameter ratio, and AM angle were analyzed as potential criteria for the diagnosis of NCS. Although the beak sign and LRV diameter ratio showed the highest diagnostic accuracy among those CT parameters, the LRV diameter
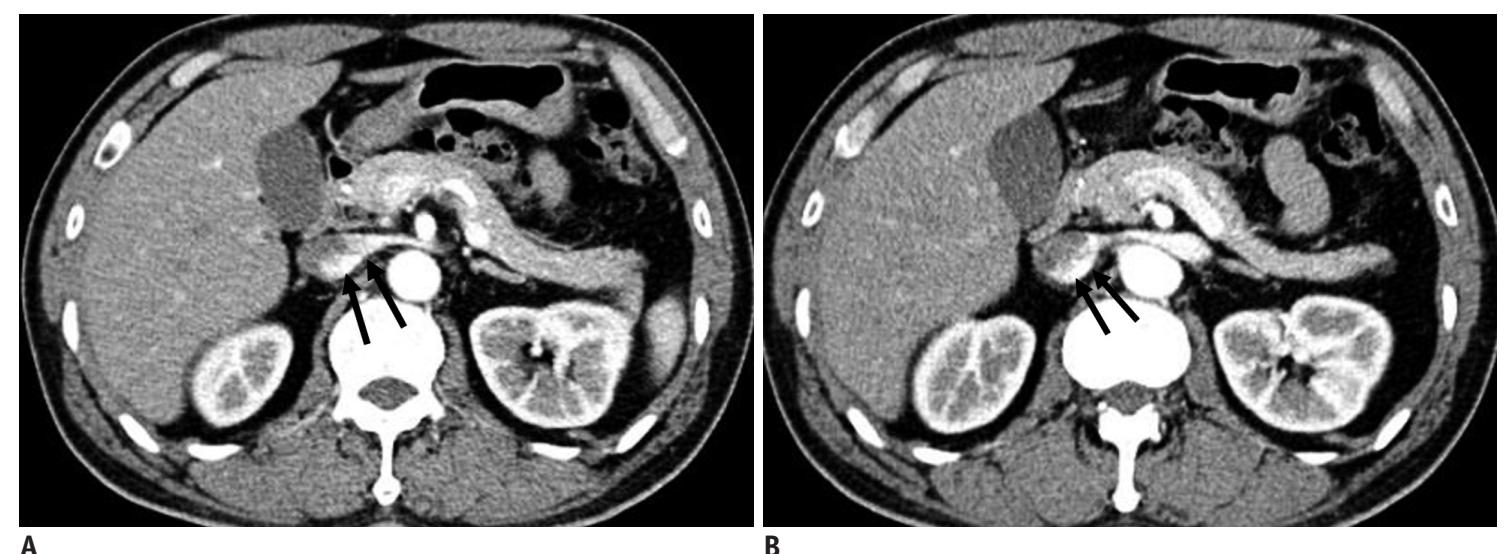

A

B
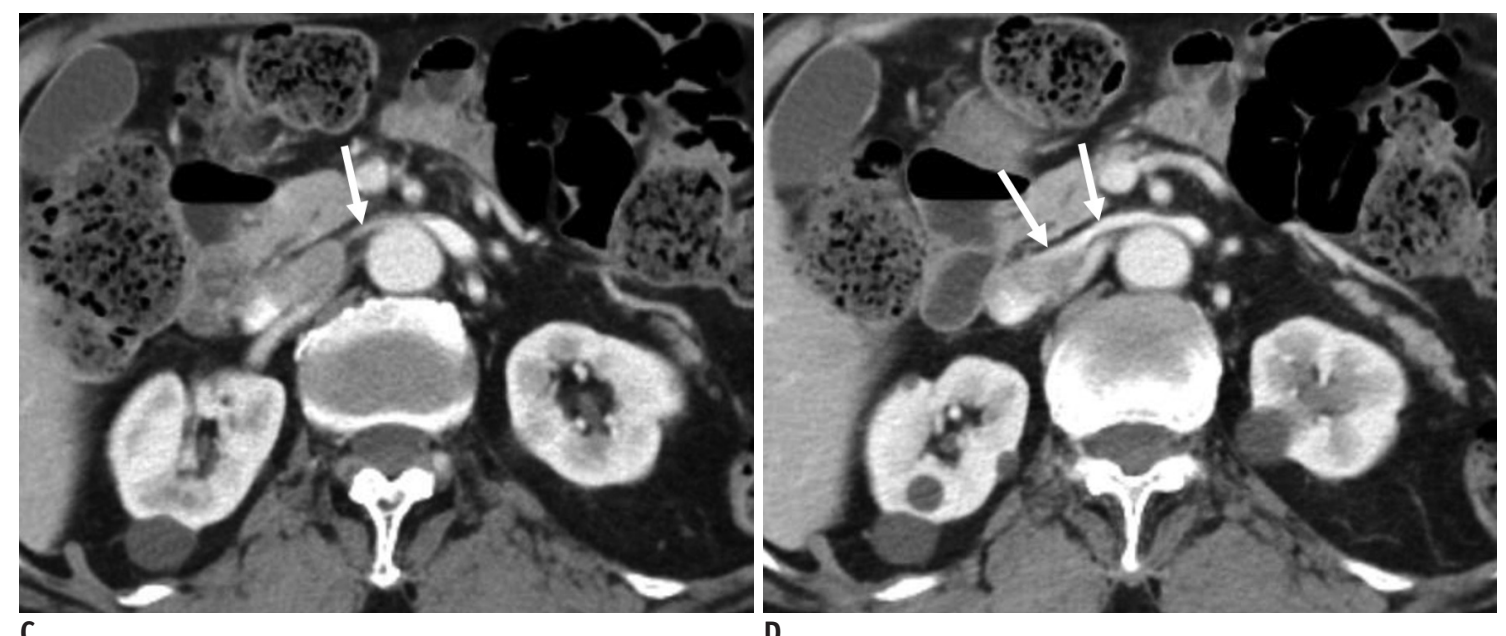

Fig. 8. Preferential flow of contrast-opacified venous flow on CECT.

A, B. 48-year-old male without hematuria. CECT images in early cortical phase show contrast-opacified venous flow into IVC along dependent posterior aspect of LRV and IVC (arrows). C, D. 82-year-old male with microscopic hematuria. CECT images in early cortical phase show contrastopacified venous flow into IVC along non-dependent anterior aspect of LRV and IVC (arrows). PV of LRV at AM portion measured by Doppler US was $133 \mathrm{~cm} / \mathrm{s}$ (not shown). 
ratio showed a lower sensitivity than the other parameters. Therefore, we suggested that beak sign can be considered as a practically useful feature in CT diagnosis of NCS (Fig. 7D). Another important CT feature for the diagnosis of NCS is a contrast-jetting phenomenon across the AM portion of the LRV in the early cortical phase of CECT (Figs. 7D, 8). In this early phase of CECT, we can observe the flow of contrastopacified blood from the LRV into the IVC. In a normal population, contrast-opacified blood moves across the AM portion of the LRV in a plug flow, or bulk movement pattern, to the IVC (Fig. 7A). In NCS patients, however, the LRV often shows significant compression, with a beak sign and jetting of contrast-opacified flow across the AM portion of the LRV (Figs. 7D, 8). Sometimes, there are phenomena of preferential contrast-opacified blood flow along the dependent posterior portion of the IVC in normal individuals (Fig. 7B, C). However, in NCS patients, preferential flow of contrast-opacified flow may occur along the anterior non-dependent portion of the IVC due to high flow velocity (Fig. 8C, D).

\section{Nutcracker Syndrome Versus Varicocele or Pelvic Congestion Syndrome}

Varicocele and pelvic congestion syndrome (PCS) occur when there is reflux of blood flow into the gonadal veins due to incompetence of venous valve function in men and women, respectively. Although these conditions can occur with or without NCP, the conditions are more severe and
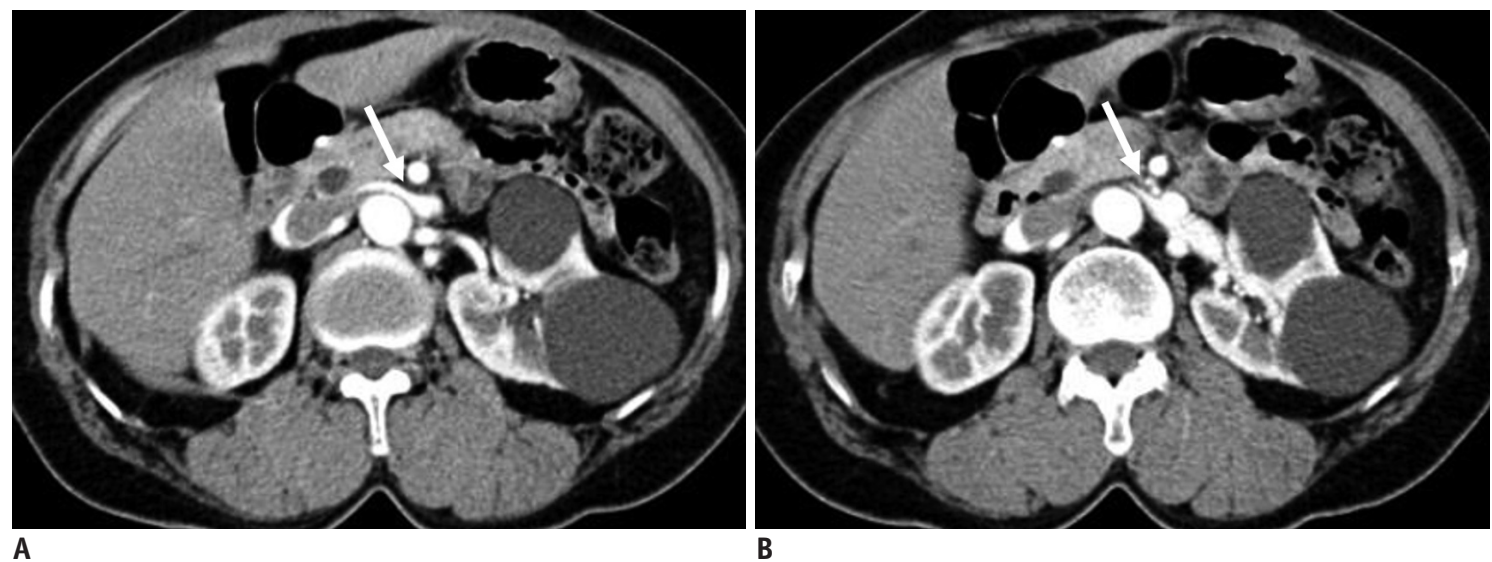

A
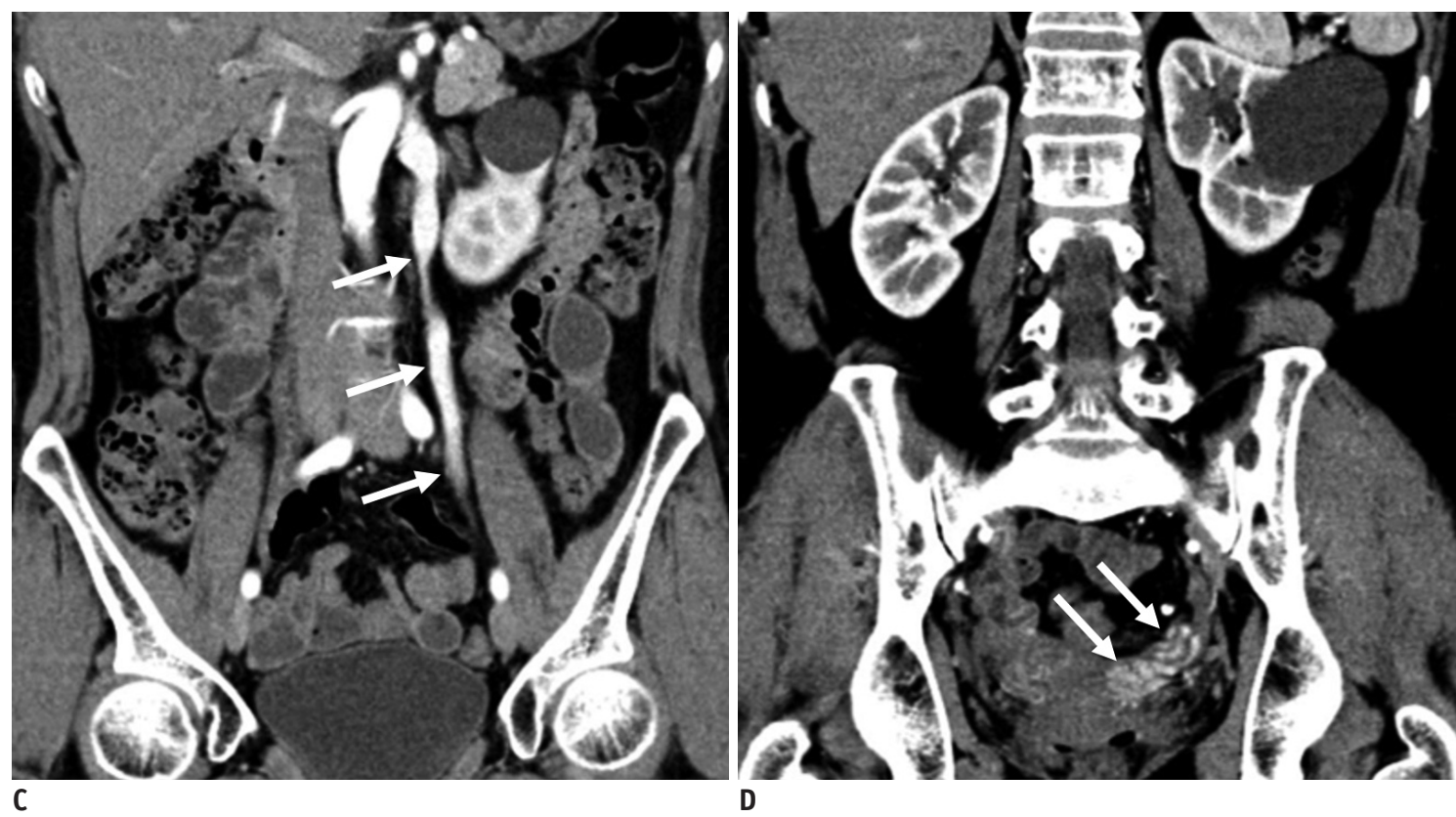

Fig. 9. 59-year-old female with concurrent NCS and pelvic congestion syndrome. Patient complained of persistent microscopic hematuria and chronic pelvic pain.

A, B. CECT images show compression of LRV at AM portion (arrows). C, D. CECT images in coronal plane show regurgitation of contrast-opacified LRV flow into left gonadal vein and pelvic veins (arrows). 
prone to recur after treatment if NCP is associated with varicocele or PCS, due to the pressure gradient caused by NCP (39-42). Because gonadal veins are important collateral pathways for relieving hypertension of the LRV in NCS patients, NCS is uncommon in patients with varicocele or PCS (43). However, some NCS patients also have varicocele or PCS (Fig. 9). Furthermore, there are also cases in which both NCS and SMA syndrome co-exist $(44,45)$.

\section{Treatment of Nutcracker Syndrome}

In young patients with NCS, symptoms usually improve as the patients get older and gains weight. A large amount of intra-abdominal fat may act as a cushion within the AM angle. In addition, when collateral venous pathways develop, renal venous hypertension may be relieved. Therefore, reassurance and general supportive care are treatment options in most cases with NCS $(12,28,46)$. However, if hematuria is severe and persistent, surgical or other interventional management may be considered $(5,28$, $35,38,47-52)$ although the effectiveness of these surgical or interventional treatments is not yet fully established.

\section{CONCLUSION}

NCS should be considered as a causative condition in patients with unexplained hematuria, either gross or microscopic. For the diagnosis of NCS, Doppler US can be helpful. For Doppler US, LRV should be carefully examined to measure the PV of the LRV at the AM portion. If the PV at the AM portion is higher than 5 times that at the hilar portion, we may suggest NCS as a cause of hematuria.

On CECT, there are several useful CT features that indicate significant LRV compression at the AM portion. These include the beak sign of the LRV and the contrast-jetting phenomenon. Invasive venography, for the measurement of the pressure gradient between the LRV and IVC, may not be necessary for the diagnosis of NCS if we utilize Doppler US and CECT properly in patients who are suspected to have NCS.

\section{Conflicts of Interest}

The author has no potential conflicts of interest to disclose.

\section{ORCID iD}

Seung Hyup Kim

https://orcid.org/0000-0002-9339-5907

\section{REFERENCES}

1. El-Sadr AR, Mina E. Anatomical and surgical aspects in the operative management of varicocele. Urol Cutaneous Rev 1950;54:257-262

2. Chait A, Matasar KW, Fabian CE, Mellins HZ. Vascular impressions on the ureters. Am J Roentgenol Radium Ther Nucl Med 1971;111:729-749

3. de Schepper A. ["Nutcracker" phenomenon of the renal vein and venous pathology of the left kidney]. J Belge Radiol 1972;55:507-511

4. Welsch T, Büchler MW, Kienle P. Recalling superior mesenteric artery syndrome. Dig Surg 2007;24:149-156

5. Ananthan K, Onida S, Davies AH. Nutcracker syndrome: an update on current diagnostic criteria and management guidelines. Eur J Vasc Endovasc Surg 2017;53:886-894

6. Nishimura Y, Fushiki M, Yoshida M, Nakamura K, Imai M, Ono T, et al. Left renal vein hypertension in patients with left renal bleeding of unknown origin. Radiology 1986;160:663-667

7. Kim SH, Cho SW, Kim HD, Chung JW, Park JH, Han MC. Nutcracker syndrome: diagnosis with Doppler US. Radiology 1996;198:93-97

8. Cheon JE, Kim WS, Kim IO, Kim SH, Yeon KM, Ha IS, et al. Nutcracker syndrome in children with gross haematuria: Doppler sonographic evaluation of the left renal vein. Pediatr Radiol 2006;36:682-686

9. Kim KW, Cho JY, Kim SH, Yoon JH, Kim DS, Chung JW, et al. Diagnostic value of computed tomographic findings of nutcracker syndrome: correlation with renal venography and renocaval pressure gradients. Eur J Radiol 2011;80:648-654

10. Kurklinsky AK, Rooke TW. Nutcracker phenomenon and nutcracker syndrome. Mayo Clin Proc 2010;85:552-559

11. Beinart C, Sniderman KW, Saddekni S, Weiner M, Vaughan ED Jr, Sos TA. Left renal vein hypertension: a cause of occult hematuria. Radiology 1982;145:647-650

12. Oteki T, Nagase $S$, Hirayama A, Sugimoto $H$, Hirayama K, Hattori $\mathrm{K}$, et al. Nutcracker syndrome associated with severe anemia and mild proteinuria. Clin Nephrol 2004;62:62-65

13. Trambert JJ, Rabin AM, Weiss KL, Tein AB. Pericaliceal varices due to the nutcracker phenomenon. AJR Am J Roentgenol 1990;154:305-306

14. Cho BS, Choi YM, Kang HH, Park SJ, Lim JW, Yoon TY. Diagnosis of nut-cracker phenomenon using renal Doppler ultrasound in orthostatic proteinuria. Nephrol Dial Transplant 2001;16:1620-1625

15. Park SJ, Lim JW, Cho BS, Yoon TY, Oh JH. Nutcracker syndrome in children with orthostatic proteinuria: diagnosis on the basis of Doppler sonography. J Ultrasound Med 2002;21:39-45

16. Pournasiri Z. The nutcracker syndrome as a rare cause of chronic abdominal pain: a case report. J Compr Ped 2016; 7:e39741

17. Taktak A, Hakan Demirkan T, Acar B, Gu R G, Köksoy A, Uncu N, et al. Clinico-radiological correlation of nutcracker syndrome: a single centre experience. Arch Argent Pediatr 2017;115:165- 
168

18. Liebl R. Nutcracker phenomenon or nutcracker syndrome? Nephrol Dial Transplant 2005;20:2009; author reply 2009

19. Buschi AJ, Harrison RB, Norman A, Brenbridge AG, Williamson $B R$, Gentry RR, et al. Distended left renal vein: $C T /$ sonographic normal variant. AJR Am J Roentgenol 1980;135:339-342

20. Zerin JM, Hernandez RJ, Sedman AB, Kelsch RC. "Dilatation" of the left renal vein on computed tomography in children: a normal variant. Pediatr Radiol 1991;21:267-269

21. Sebro K, Goetz L, Persaud S. Nutcracker syndrome: a rare and potentially under diagnosed cause of haematuria. Case Rep Surg Invasive Proced 2017;1:4-6

22. He Y, Wu Z, Chen S, Tian L, Li D, Li M, et al. Nutcracker syndrome-How well do we know it? Urology 2014;83:12-17

23. Wendel RG, Crawford ED, Hehman KN. The "nutcracker" phenomenon: an unusual cause for renal varicosities with hematuria. J Urol 1980;123:761-763

24. Hayashi M, Kume T, Nihira H. Abnormalities of renal venous system and unexplained renal hematuria. J Urol 1980;124:1216

25. Lau JLT, Lo R, Chan FL, Wong KK. The posterior "nutcracker": hematuria secondary to retroaortic left renal vein. Urology 1986;28:437-439

26. Ali-El-Dein B, Osman Y, Shehab El-Din AB, El-Diasty T, Mansour 0, Ghoneim MA. Anterior and posterior nutcracker syndrome: a report on 11 cases. Transplant Proc 2003;35:851853

27. Skeik N, Gloviczki P, Macedo TA. Posterior nutcracker syndrome. Vasc Endovascular Surg 2011;45:749-755

28. Özkan MB, Ceyhan Bilgici M, Hayalioglu E. Anterior and posterior nutcracker syndrome accompanying left circumaortic renal vein in an adolescent: case report. Arch Argent Pediatr 2016;114:e114-e116

29. Naito M, Terayama H, Nakamura Y, Hayashi S, Miyaki T, Itoh M. Left testicular artery arching over the ipsilateral renal vein. Asian J Androl 2006;8:107-110

30. Radisic MV, Feldman D, Diaz C, Froment RO. Unexplained hematuria during pregnancy: right-sided nutcracker phenomenon. Int Urol Nephrol 2007;39:709-711

31. Beinart C, Sniderman KW, Tamura S, Vaughan ED Jr, Sos TA. Left renal vein to inferior vena cava pressure relationship in humans. J Urol 1982;127:1070-1071

32. Hangge PT, Gupta N, Khurana A, Quencer KB, Albadawi H, Alzubaidi $\mathrm{SJ}$, et al. Degree of left renal vein compression predicts nutcracker syndrome. J Clin Med 2018;7. pii: E107

33. Fong JKK, Poh ACC, Tan AGS, Taneja R. Imaging findings and clinical features of abdominal vascular compression syndromes. AJR Am J Roentgenol 2014;203:29-36

34. Orczyk K, Wysiadecki G, Majos A, Stefańczyk L, Topol M, Polguj M. What each clinical anatomist has to know about left renal vein entrapment syndrome (nutcracker syndrome): a review of the most important findings. Biomed Res Int 2017 Dec 11 [Epub]. https://doi.org/10.1155/2017/1746570

35. Ahmed K, Sampath R, Khan MS. Current trends in the diagnosis and management of renal nutcracker syndrome: a review. Eur J Vasc Endovasc Surg 2006;31:410-416

36. Hohenfellner M, Steinbach F, Schultz-Lampel D, Schantzen W, Walter K, Cramer BM, et al. The nutcracker syndrome: new aspects of pathophysiology, diagnosis and treatment. J Urol 1991; 146:685-688

37. Fitoz S, Ekim M, Ozcakar ZB, Elhan AH, Yalcinkaya F. Nutcracker syndrome in children: the role of upright position examination and superior mesenteric artery angle measurement in the diagnosis. J Ultrasound Med 2007;26:573580

38. Stewart BH, Reiman G. Left renal venous hypertension "nutcracker" syndrome: managed by direct renocaval reimplantation. Urology 1982;20:365-369

39. Kim SH, Park JH, Han MC, Paick JS. Embolization of the internal spermatic vein in varicocele: significance of venous pressure. Cardiovasc Intervent Radiol 1992;15:102-106; commentary 106-107

40. Zerhouni EA, Siegelman SS, Walsh PC, White RI. Elevated pressure in the left renal vein in patients with varicocele: preliminary observations. J Urol 1980;123:512-513

41. Pallwein L, Pinggera G, Schuster AH, Klauser A, Weirich HG, Recheis $W$, et al. The influence of left renal vein entrapment on outcome after surgical varicocele repair: a color Doppler sonographic demonstration. J Ultrasound Med 2004;23:595601

42. Scultetus AH, Villavicencio JL, Gillespie DL. The nutcracker syndrome: its role in the pelvic venous disorders. J Vasc Surg 2001;34:812-819

43. Kim WS, Cheon JE, Kim IO, Kim SH, Yeon KM, Kim KM, et al. Hemodynamic investigation of the left renal vein in pediatric varicocele: Doppler US, venography, and pressure measurements. Radiology 2006;241:228-234

44. Barsoum MK, Shepherd RFJ, Welch TJ. Patient with both Wilkie syndrome and nutcracker syndrome. Vasc Med 2008;13:247-250

45. Inal M, Unal Daphan B, Karadeniz Bilgili MY. Superior mesenteric artery syndrome accompanying with nutcracker syndrome: a case report. Iran Red Crescent Med J 2014; 16:e14755

46. Javaid MM, Ong CC, Subramanian S. Blood in urine: a hard nut to crack. Am J Med 2017;130:e89-e91

47. Sugimoto I, Ohta T, Ishibashi H, Takeuchi N, Nagata Y, Honda $Y$. Left renal vein entrapment syndrome (nutcracker syndrome) treated with left renal vein transposition. Jpn J Vasc Surg 2001;10:503-507

48. Barnes RW, Fleisher HL 3rd, Redman JF, Smith JW, Harshfield $\mathrm{DL}$, Ferris EJ. Mesoaortic compression of the left renal vein (the so-called nutcracker syndrome): repair by a new stenting procedure. J Vasc Surg 1988;8:415-421

49. Shokeir AA, El-Diasty TA, Ghoneim MA. The nutcracker syndrome: new methods of diagnosis and treatment. $\mathrm{Br} J \mathrm{Urol}$ 1994; 74:139-143

50. Reed NR, Kalra M, Bower TC, Vrtiska TJ, Ricotta JJ 2nd, 
Gloviczki P. Left renal vein transposition for nutcracker syndrome. J Vasc Surg 2009;49:386-393; discussion 393-394

51. Xu D, Liu Y, Gao Y, Zhang L, Wang J, Che J, et al.

Management of renal nutcracker syndrome by retroperitoneal laparoscopic nephrectomy with ex vivo autograft repair and autotransplantation: a case report and review of the literature. J Med Case Rep 2009;3:82

52. Hartung 0 . Nutcracker syndrome. Phlebolymphology $2009 ; 16: 246-252$ 